\title{
Shara McCallum
}

\section{Persephone Sets the Record Straight}

You are all the rage these days, mother. Everywhere I turn, I hear

Demeter in mourning, Demeter grieving ... poor Demeter.

Always craving the spotlight, I know this is what you wanted: your face on the front page of all the papers; gossip

columns filled with juicy tidbits on what life was like before winter, old hags in the grocery store, whispering, how she's let the flowers go,

while young women hover in their gardens, fearing their hibiscus will be next on your hit list. After all these summers,

you still won't come clean.

Passing me iced tea, instead you ask, how's the redecorating? are you expanding

to make room for little ones?

Fanning away flies, you avoid my eyes, saying, I've so longed to be a grandma, you know.

For God's sake, mother, 
can't you tell me the truth now it's done?

Just once, tell me

how you put me in that field

knowing he'd come,

that you made snow fall

everywhere to cover your tracks,

that the leaves die still

because you can't punish him

for confirming your suspicions:

not wanting you,

he took me instead.

Of course I ate those seeds.

Who wouldn't have

exchanged one hell for another?

\section{In the Garden of Banana and Cocoanut Trees}

Before the woman's hips

would come to sashay

to other rhythms,

before the man's hands

would grow still, leave

the hollowed-out wood body,

before she would take lovers

over her children,

before his mind would lose

itself to songs

of angels and demons,

before the gospel and herb,

there was my mother,

cooking cornmeal porridge,

plantains and callaloo for later, 